\title{
3 Research Square

\section{A Science-Policy Framework for a Green Economic Recovery After the COVID-19 Pandemic}

Theodoros Zachariadis ( $\square$ t.zachariadis@cyi.ac.cy )

The Cyprus Institute

\section{Elias Giannakis}

The Cyprus Institute

\section{Constantinos Taliotis}

The Cyprus Institute https://orcid.org/0000-0003-4022-5506

\section{Marios Karmellos}

The Cyprus Institute

\section{Nestor Fylaktos}

The Cyprus Institute

\section{Mark Howells}

Loughborough University https://orcid.org/0000-0001-6419-4957

\section{William Blyth}

Department for International Development

\section{Stephane Hallegatte}

World Bank https://orcid.org/0000-0002-1781-4268

\section{Analysis}

Keywords: Climate-compatible growth, Energy systems model, Input-output model, Multi-criteria decision analysis, Policy formulation, Stakeholder engagement, Sustainable Development Goals

Posted Date: January 13th, 2021

DOI: https://doi.org/10.21203/rs.3.rs-137855/v1

License: (c) This work is licensed under a Creative Commons Attribution 4.0 International License.

Read Full License 
2

A Science-Policy Framework for a Green Economic Recovery After the COVID-19 Pandemic

\author{
Theodoros Zachariadis*, Elias Giannakis, Constantinos Taliotis, \\ Marios Karmellos and Nestor Fylaktos \\ Energy, Environment and Water Research Centre, The Cyprus Institute, Cyprus \\ Mark Howells \\ Loughborough University and Imperial College London, UK \\ Will Blyth \\ Department for International Development, UK \\ Stéphane Hallegatte \\ World Bank
}

\title{
ABSTRACT
}

As current production and consumption patterns of humanity exceed planetary boundaries, many opinion leaders have stressed the need to adopt green economic stimulus policies in the aftermath of the COVID-19 pandemic. Here, we provide an integrated multi-stakeholder framework to design an economic recovery strategy aligned with sustainability objectives. We first employ quantitative energy and economic models and then design a multi-criteria decision process in which we engage social actors from government, enterprises, and civil society. As a case study, we select green recovery measures that are relevant for a European Union country and assess their appropriateness with numerous criteria related to socio-economic and environmental sustainability and resilience. Results highlight trade-offs between immediate and long-run effects, between economic and environmental objectives, and between expert evidence and societal priorities. Importantly, we find that a 'returnto-normal' economic stimulus is not only environmentally unsustainable but also economically inferior to most green recovery schemes.

Keywords: Climate-compatible growth; Energy systems model; Input-output model; Multi-criteria decision analysis; Policy formulation; Stakeholder engagement; Sustainable Development Goals

\footnotetext{
* Corresponding author. Address: The Cyprus Institute, Konstantinou Kavafi 20, 2121 Aglantzia, Nicosia, Cyprus. Email: t.zachariadis@cyi.ac.cy
} 
Since mid-2020, despite the persistence of the COVID-19 pandemic, the response of governments around the world has partly moved from the provision of immediate relief to the design and implementation of economic recovery measures for the short and medium term. Leaders of international organisations have stressed the importance of adopting green economic stimulus policies in line with the United Nations Sustainable Development Goals and the Paris agreement on Climate Change, as greener economies are more resilient to climate change, social unrest, and epidemics ${ }^{1-4}$. Global economic support for relief and recovery from the pandemic has risen to significant levels since spring 2020 - but as regards the conformity of such stimulus measures with climate compatible growth (CCG) and broader sustainability objectives, the picture is mixed ${ }^{5,6}$.

Here we develop a novel integrated assessment framework for the design of an economic recovery strategy that could have promising impacts on environmental and socio-economic sustainability. As shown in Figure 1, this involves multi-criteria decision analysis, which incorporates both quantitative data derived from models and qualitative input provided by several stakeholders. The use of qualitative input is not only necessary because models cannot adequately simulate all possible impacts; it is also essential for increasing the likelihood of social acceptance of the recovery interventions to be proposed, by avoiding to rely solely on knowledge silos of academic experts or governmental policy makers. This is in line with the need for broader mobilisation of society for the transition to sustainability ${ }^{7}$. Although we applied this approach in the case of Cyprus, an EU member state in the Eastern Mediterranean, the framework has general application, and the underlying tools and processes are selected in such a way as to allow their adoption in other national or regional contexts. This science-policy framework involves regular interaction with societal actors, which can help highlight the importance of thinking beyond purely short-term recovery measures and considering investments and reforms that may take time to materialise but are essential for meeting medium- and 
53 long-term environmental objectives ${ }^{8}$. A short-term recovery plan, no matter how green it is, cannot

54 deliver the sustainability transition by itself; it has to be complemented by structural reforms that can

55 deliver environmental and economic benefits over the longer term ${ }^{9}$. In our approach we highlighted

56 this aspect to national stakeholders, some of whom were understandably interested in mitigating the

57 immediate impacts of the pandemic and paid less attention to long-term green reforms. Based on

58 quantitative evidence, we also emphasised the mediocre performance of a 'return-to-normal'

59 economic stimulus, not only in environmental but also in economic terms. To encourage ownership

60 of the measures by national decision makers we built on policies and measures that are largely based

61 on existing national plans so that stakeholders are familiar with such interventions. This increases the

62 likelihood for adoption of these measures in the national recovery strategy.

63

64 


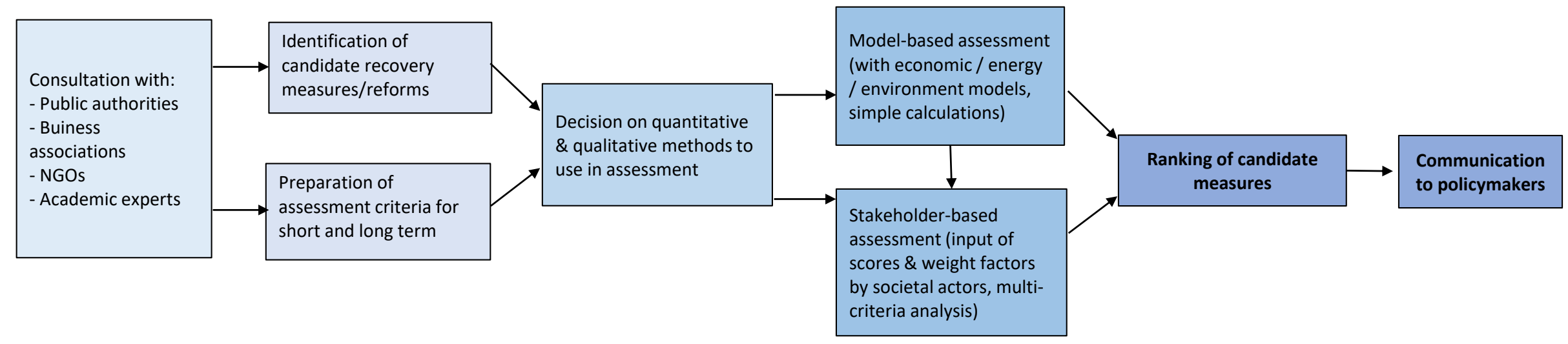

Figure 1: Approach to designing and assessing a green economic recovery strategy 


\section{Results}

2 After extensive deliberations with stakeholders from the public and private sector since the outbreak

3 of the pandemic, we arrived at thirteen recovery measures to evaluate further; these are listed in

4 Table 1 . We used a wide array of sustainability criteria for assessing these thirteen interventions,

5 adapted from a comprehensive checklist that was developed by the World Bank especially for post-

6 COVID19 economic stimulus interventions ${ }^{10}$. The list of criteria used in this paper is presented in Table

7 2. As the EU decided in 2019 to explicitly include the seventeen United Nations Sustainable

8 Development Goals (SDGs) in its regular macroeconomic monitoring procedure, and due to the

9 universality of SDGs ${ }^{11}$, Table 2 also includes an indication of the SDGs addressed by each sustainability

10 criterion used in this analysis. 


\begin{tabular}{|c|c|c|c|c|}
\hline Name of measure & Sector & $\begin{array}{l}\text { Investment } \\
\text { cost } 2020- \\
2022 \text { (M€) }\end{array}$ & $\begin{array}{l}\text { Investment } \\
\text { cost 2020- } \\
2030 \text { (M€) }\end{array}$ & $\begin{array}{l}\text { of which } \\
\text { from public } \\
\text { funds }\end{array}$ \\
\hline M1. Immediate launch of grants for energy renovations of buildings from unused budget of 2020-21 & Buildings & 30 & 30 & $50 \%$ \\
\hline M2. New grant scheme for energy renovations of existing buildings, 2021-27 & Buildings & 70 & 140 & $50 \%$ \\
\hline $\begin{array}{l}\text { M3. Grants for energy renovations of buildings under construction for upgrade to Near-Zero Energy } \\
\text { Buildings }\end{array}$ & Buildings & 70 & 70 & $50 \%$ \\
\hline M4. Installation of smart electricity meters & Electricity & 35 & 55 & $100 \%$ \\
\hline M5. Virtual net billing for encouragement of photovoltaic installations by enterprises & Electricity & 29 & 136 & $0 \%$ \\
\hline M6. Subsidy to loans of businesses certified with an environmental management system & Industry & 2 & 2 & 100 \\
\hline M7. Business4Climate scheme - grants to enterprises with a verified low-carbon action plan up to 2030 & Industry & 5 & 10 & $30 \%$ \\
\hline M8. Implementation of existing Sustainable Urban Mobility Plans (SUMP) & Transport & 80 & 100 & $100 \%$ \\
\hline M9. Construction of tram in the capital city of Nicosia & Transport & 0 & 225 & $100 \%$ \\
\hline M10. Scrappage scheme for old cars to be replaced with battery electric vehicles & Transport & 12 & 12 & $30 \%$ \\
\hline M11. Replacement of streetlights in municipalities and villages with energy efficient lighting & Electricity & 45 & 45 & $100 \%$ \\
\hline M12. Tree planting along urban and intercity roads & Nature & 17 & 85 & $100 \%$ \\
\hline M13. Fiscally neutral carbon taxation for economic sectors out of the EU Emissions Trading System & Horizontal & 0.5 & 0.5 & 100 \\
\hline Tota & & 395 & 911 & \\
\hline
\end{tabular}

3 Note: Costs are expressed in million Euros at constant prices of year 2020.

4 
i) Performance criteria for the short term (for the next 2 years):

\begin{tabular}{|c|c|c|c|}
\hline & Short name & Explanation & Related SDGs \\
\hline \multirow{3}{*}{ 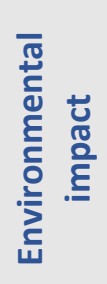 } & Energy & Energy savings (ktoe) per million Euros invested & 7 \\
\hline & $\mathrm{CO2}$ & $\mathrm{CO}_{2}$ emission savings (tn) per million Euros invested & 13 \\
\hline & Other Environmental Impact & $\begin{array}{l}\text { Other short-term environmental impact (on air quality, nature, water resources, land } \\
\text { productivity, biodiversity etc) }\end{array}$ & $3,6,11$ \\
\hline \multirow{8}{*}{ 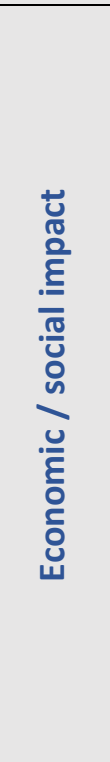 } & Economic multiplier & Economic output generation (million $€$ ) per million Euros invested & 8 \\
\hline & Jobs & Net employment generation (persons) per million Euros invested & 8 \\
\hline & Demand in affected sectors & $\begin{array}{l}\text { Does the initiative generate demand in the most affected sectors? Or does this initiative } \\
\text { target new or different sectors? If in a different sector, can the workforce easily shift to } \\
\text { this new sector? Does the initiative include measures to facilitate the transition of } \\
\text { workers and the required investments? }\end{array}$ & 4,8 \\
\hline & Time to Implement & $\begin{array}{l}\text { How long will it take to fully implement this initiative and to create jobs and activity } \\
\text { (including project design, consultation processes, budget mobilization, procurement, } \\
\text { etc.)? }\end{array}$ & 8 \\
\hline & Infrastructure \& Productivity & $\begin{array}{l}\text { Does the measure improve existing infrastructure? Does this affect productivity in the } \\
\text { short term? }\end{array}$ & 9 \\
\hline & Technical feasibility & Is the intervention technically feasible with the country's capacity and know-how? & \\
\hline & Affordability & $\begin{array}{l}\text { Is there a risk that vulnerable households or firms will incur high costs due to the } \\
\text { measure? }\end{array}$ & 1,10 \\
\hline & Social acceptance & $\begin{array}{l}\text { Is the measure socially acceptable? Can it contribute to social objectives like reducing } \\
\text { poverty and precarity? }\end{array}$ & 1,10 \\
\hline
\end{tabular}


Performance criteria for the longer term (mostly for 2030):

\begin{tabular}{|c|c|c|c|}
\hline & Short name & Explanation & Related SDGs \\
\hline \multirow{4}{*}{ 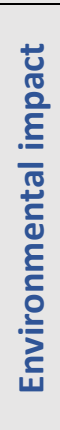 } & Energy & Energy savings (ktoe) per million Euros invested & 7 \\
\hline & $\mathrm{CO2}$ & $\mathrm{CO}_{2}$ emission savings (tn) per million Euros invested & 13 \\
\hline & $\begin{array}{l}\text { Low-carbon technologies / } \\
\text { strategies }\end{array}$ & $\begin{array}{l}\text { Does the intervention provide the technical means to better integrate or employ low- } \\
\text { carbon technologies or strategies (for instance, through improvements to transmission } \\
\text { and distribution infrastructure, public transit infrastructure, sidewalks or bike lanes, or } \\
\text { by promoting denser urban development) that may yield benefits beyond the year } \\
\mathbf{2 0 3 0} \text { ? Does it contribute to a deep decarbonisation objective by } \mathbf{2 0 5 0 ?}\end{array}$ & 13,15 \\
\hline & Other Environmental Impact & $\begin{array}{l}\text { Other short-term environmental impact (on air quality, nature, water resources, land } \\
\text { productivity, biodiversity etc) }\end{array}$ & $3,6,11,15$ \\
\hline \multirow{8}{*}{ 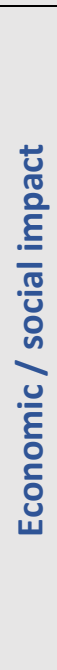 } & Economic multiplier & Economic output generation (million $€$ ) per million Euros invested & 8 \\
\hline & Jobs & Net employment generation (persons) per million Euros invested & 8 \\
\hline & Energy security & Does the intervention increase local/national energy security? & 7 \\
\hline & Infrastructure \& Productivity & $\begin{array}{l}\text { Will the intervention improve local economic productivity through access to better, } \\
\text { more reliable infrastructure services? }\end{array}$ & 9 \\
\hline & R\&D and innovation & Can the intervention spur R\&D or innovation in the specific technologies? & 9 \\
\hline & Market Failures & $\begin{array}{l}\text { Will the intervention address market failures, such as market distorting subsidies, } \\
\text { pricing that fails to account for externalities, etc.? }\end{array}$ & 8 \\
\hline & Economic / Climate Resilience & $\begin{array}{l}\text { Does the intervention improve socio-economic resilience, that is, the ability of the } \\
\text { population to cope with and recover from shocks? Does it improve their adaptive } \\
\text { capacity, that is their ability to reduce negative impacts (such as adapting buildings to } \\
\text { improve resilience to extreme temperature)? }\end{array}$ & $1,8,10,11$ \\
\hline & Decarbonisation / Effect on NDC & $\begin{array}{l}\text { Does the measure contribute substantially to decarbonisation of the economy by } \\
2030 \text { ? Does it significantly affect the country's NDC to be submitted to UNFCCC? }\end{array}$ & 12,13 \\
\hline
\end{tabular}




\section{Model-based results}

3 Some of the criteria of Table 2 - those related to impacts of green measures on energy use, carbon

4 dioxide emissions, economic output, and jobs - were computed through specialised models that had been already used for national impact assessments and were known to public authorities. We employed an energy model and an economic model for this purpose. The energy systems model was OSeMOSYS ${ }^{12}$, a transparent, open-source modelling system for energy planning. Performance was measured in terms of energy and carbon emission savings per million of Euros invested in each measure. According to model results, some of the best-performing measures in the short-term are also the preferred ones for the longer term (up to 2030); these are carbon taxation (a regulatory measure with very low implementation costs), virtual net billing (which is also regulatory and will enable a faster deployment of decentralised solar power generation), implementation of urban mobility plans, and loans to business with certified environmental management systems. In the short run, some further measures on energy efficiency upgrades also have good carbon abatement potential per unit of investment.

To simulate the impact of each recovery measure on economic growth and employment, an economic input-output model was used. The impact of a policy depends on how much investments in a sector affect demand for goods/services in other sectors, what part of intermediate inputs of a sector takes place in the country, which production activities are displaced, and how labour-intensive are the sectors affected by new investments, compared to that of displaced activities. Figure 2 illustrates some of these results by displaying graphically economic effects versus employment and environmental effects of the modelled interventions. The impact is relatively higher in the short run due to the frontloaded allocation of investment expenditures in 2021-22, both because this is what a recovery plan means to be and because a strong economy-wide rebound was assumed for these two years. 
1 Results confirm once more the conclusion that Barbier ${ }^{9}$, Popp et al. ${ }^{13}$, and Strand and Toman ${ }^{8}$ have drawn on the basis of ex-post assessments around the world: measures performing best in the short run are partly different from those with the largest positive effect in the longer term. With regard to economic output generation, in the short-run measures M4 and M5 (installation of smart electricity meters and virtual net billing respectively) create the highest economy-wide effects relative to the reference scenario; for every million Euro $(\mathrm{M} €)$ invested for these interventions, the total output of the economy increases by $1.45 \mathrm{M} €$ and $1.44 \mathrm{M} €$ respectively in $2022 / 23$. Two measures that could boost short-term output, M9 and M12, are not included - M9 because the construction of the tram line is expected to start after 2023, and M12 because tree planting has not been simulated with the IO model due to lack of data. In the long run, virtual net billing (M5) creates the highest economywide effects.

The impacts on employment are similar but not identical to the effect on economic output. In the short run, virtual net billing and smart meters create the highest positive effects on national employment; for every million Euro invested in either measure, about 14 new jobs are created throughout the economy. In the long-run, the virtual net billing measure still creates the highest economy-wide employment effects. On the contrary, sustainable mobility interventions M8 and M9 do not perform well in terms of employment generation, thanks to their success to shift mobility from private cars to public transport; this causes household spending for fuel and car purchases as well as for car maintenance to drop considerably, and the affected economic activities (imports of fuels and vehicles) are labour-intensive so that overall employment seems to be affected negatively.

However, such model-based seemingly undesired effects of energy efficiency measures have to be treated with caution. They should not be interpreted as suggesting to avoid energy efficiency investments that improve the economy-wide productivity of energy use. A feature of input-output economic models is the assumption of fixed technical coefficients: the combinations of inputs are 
1 and no technological progress, which is plausible when immediate policy impacts are simulated but

2 becomes less realistic when the impacts over a longer time horizon are modelled. To the extent that

3 the reduced economic output and employment in sectors such as trade of vehicles and fuels is compensated through re-training of workers and re-orientation of business activities, negative economic impacts of sustainable mobility can be overcome. More broadly, the ability of an economy to transform itself and use the resources saved to grow new sectors, or to divert saved resources to export-oriented activities as a result of increased business competitiveness, will depend on factors like people's skills, availability of financing and policy decisions - aspects that are insufficiently accounted for by this kind of economic models.

It should also be noted that the economic model does not distinguish between employment categories, so that our approach cannot include the separate impact on low-skilled and high-skilled workers, which would be important for evaluating the effect of each intervention on long-term growth prospects. Such considerations are important in view of the findings of studies that examined stimulus measures applied after the 2008-2009 economic downturn, which highlight the importance of observing differences in skills in order to properly compare alternative policies ${ }^{14}$. Moreover, job calculations do not account for the possibility that supply of skills in some sectors may not suffice to meet growing demand. For example, a construction boom due to energy renovations may be limited by a lack of skilled technicians in the country, at a time where a 'renovation wave' in buildings is foreseen across the entire Europe. Therefore, before deciding on the extent of implementation of a recovery measure, a skill mismatch analysis would be needed to ensure that human resources are available for realising this intervention.

It is particularly interesting to observe the results of the counterfactual scenario, which assumes a 'return-to-normal' economic stimulus, where all recovery funds are allocated uniformly to households and businesses, and consumption continues as before. As indicated by a red dot in Figure 2, a businessas-usual economic recovery is clearly not the preferable option; with an economic multiplier of just 
10.83 it performs better than only two out of all the green measures. It also has a mediocre effect in

2 terms of employment generation, with 6.3 new jobs per $M €$, whereas four green measures have more than double job benefits. This clearly indicates that a uniform demand stimulus is far from the most effective strategy for increasing employment in the short term. Such a finding, which has been explored by very few studies so far, is confirmed by Pollitt ${ }^{15}$ for some major EU economies (through a macro-econometric model) and by the IMF ${ }^{16}$ for the global economy (through a computable general equilibrium model). 8

\section{Multi-criteria assessment results}

Models cannot simulate all impacts, and the relative importance of each one of the criteria of Table 2 should not be determined by experts or public authorities alone. The transition to sustainability requires implementation of ambitious but actionable measures, and stakeholder participation for codeveloping a green stimulus plan is crucial in this regard. Therefore, a variety of stakeholders were invited to act as decision makers and provide input for this assessment. They were selected in order to be representative of public authorities, businesses, and civil society, and participated in a dedicated workshop that was held in October 2020. At the workshop, participants were informed in detail about the list of recovery measures and the evaluation criteria and were then provided with the respective tables to fill in, applying the multi-criteria methods shown in the methodological section of this paper.

Preferences of workshop participants varied significantly by criterion, highlighting the different priorities of each stakeholder. For example, representatives of private enterprises valued short-term criteria more strongly than long-term ones, in contrast to other stakeholders. On the other hand, some governmental stakeholders provided a higher weight to long-term environmental criteria compared to short-term ones. Overall, most decision makers assigned a higher importance to the long term than to the short term, whereas there was no consistent preference to environmental versus economic/social criteria. 
1 Figure 3 displays intermediate results of the evaluation, averaged over all stakeholders, before providing the final weighting of all criteria. The carbon tax reform (measure M13) received a high score for its environmental performance in both the short and the long term, and actions related to sustainable mobility (M8 and M9) also had a good score on long-term environmental performance. Conversely, measures M5, M6 and M7, which mainly target businesses, were assigned by participants the highest scores regarding long-term economic effectiveness.

After weighting the scores for all groups of criteria (environmental and socio-economic, short- and long-term), the final ranking is presented in Table 3, which shows that the best green recovery intervention is considered to be the fiscally neutral carbon tax reform (M13). This measure had the best results in terms of energy savings and carbon savings for the short- and long-term, which were calculated using quantitative models, but received also high evaluations from the stakeholders in several criteria - it ranked first in the individual ranking of five out of ten stakeholders. In addition, stakeholders valued measures M5, M2 and M7 (implementation of virtual net billing, energy renovations of buildings and grants to reduce the carbon footprint of enterprises) as the next most important for the sustainable development of Cyprus.

These results offer interesting insights when compared to evaluations performed informally by some of the authors, who applied a simple assessment approach to obtain a rapid overview of the preferred policies. Although the expert view of some of the authors had considered long-term infrastructure modernisation and decarbonisation interventions as important priorities, those were not among the preferred measures of stakeholders. For example, the only nature-based measure (M12 - tree planting) and the two sustainable mobility measures (M8 and M9) rank average or below-average in stakeholder preferences; this may be attributed to concerns by some stakeholders, which were orally communicated during the workshop, that these measures are unrealistic, too costly, or can only have limited effects. Another reason may be that most stakeholders considered the period to 2030 as 'longterm' and left 2050 out of sight. However, long-term sustainability objectives may require actions that 
1 start immediately. To reach an ambitious target in 2050 , such as the net carbon neutrality pledged by

2 the EU, ambitious measures are necessary already now in order to allow time for technology penetration and behavioural changes ${ }^{17,18}$.

4 A second example is the installation of smart electricity meters (M4), which may accelerate penetration of decentralised renewable electricity and allow for flexible electricity tariffs and other high-technology innovations. This was evaluated by workshop participants among the least preferable options, although the authors' expert judgement considered this a high-ranking measure. Such discrepancies are not surprising; it has been recognised in the literature that heterogeneity of stakeholders results in preferences which diverge from those of experts ${ }^{19}$.

Even when they contradict modelling results and expert opinions, these views need to be taken seriously, considering the direct experience of stakeholders and decision-makers: some measures may have lower social acceptance than experts believe, and may require more in-depth work to take into account stakeholders' concerns - for example, by considering more carefully the risks of some measures to social equity and through proper information and communication campaigns to target audiences and the broader public.

At the same time, it is interesting that a seemingly unpopular measure (carbon taxation, even if framed as fiscally neutral) received the top score among recovery measures. In view of the extensive discussions about the social acceptance of such pricing schemes worldwide ${ }^{20,21}$, this seems to be a surprising but also encouraging result, as carbon pricing is widely considered by economists as a necessary ingredient of effective decarbonisation policies. In the context of the current pandemic, Engström et al. ${ }^{22}$ call this kind of reform "excellent climate policies [which] also help deal with the coronavirus crisis by allowing reductions to labour taxes". A plausible explanation for the high score of this measure among Cypriot stakeholders is that this kind of green tax reform (comprising an increase in environmental taxes to be compensated by reductions in labour taxation) has been promoted in Cyprus by some experts since 2015, with a consistent attempt to inform governmental 
1 authorities, NGOs and trade unions about its advantages ${ }^{23}$. The resulting top performance in this

2 assessment may be an indication that targeted and well-supported information flows to diverse

3 stakeholders have been effective and may lead to societal acceptance of such a reform in the near 4 future.

5

6 


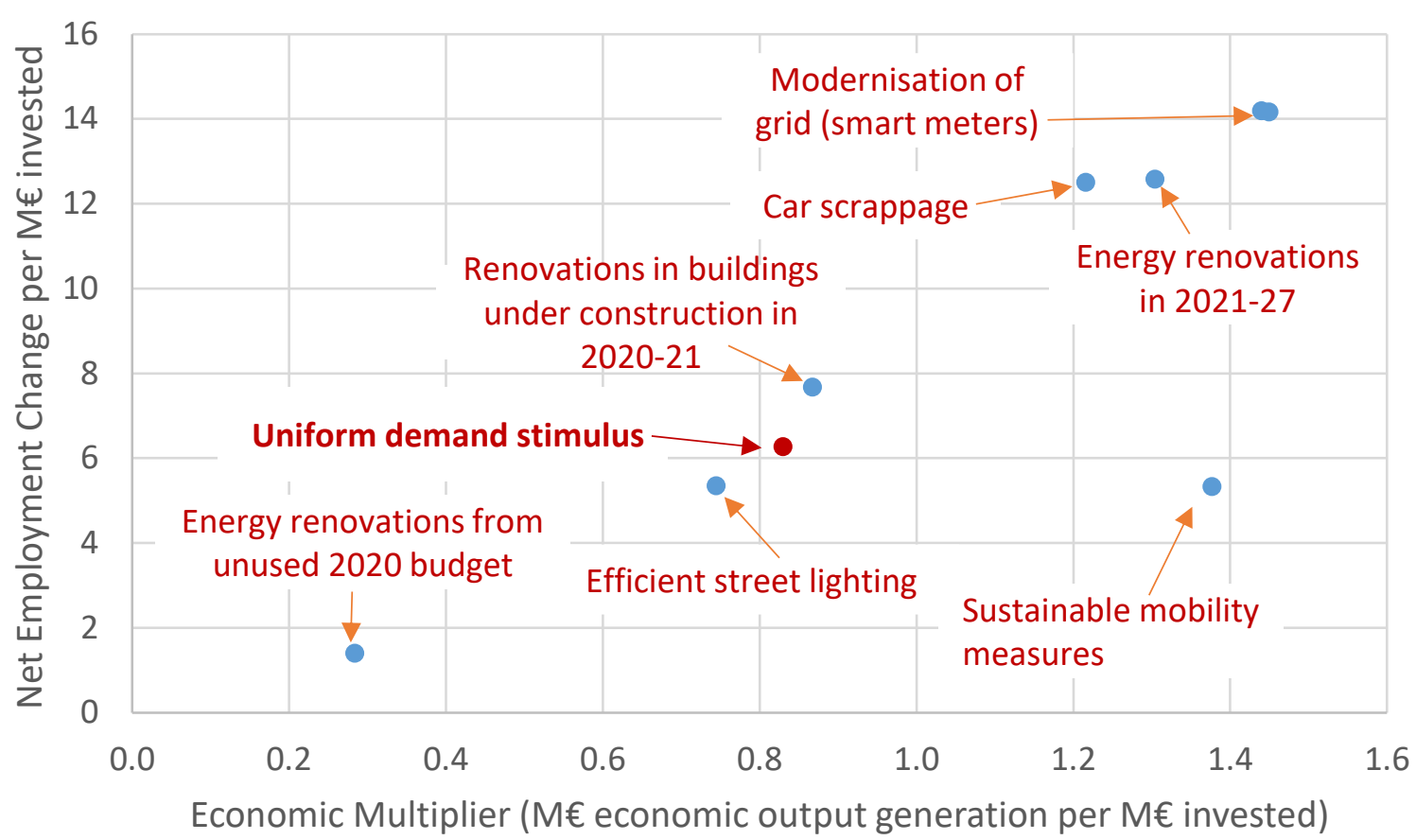

1

b

Short-Term Economic vs. Long-Term Environmental Impact of Green Recovery Measures

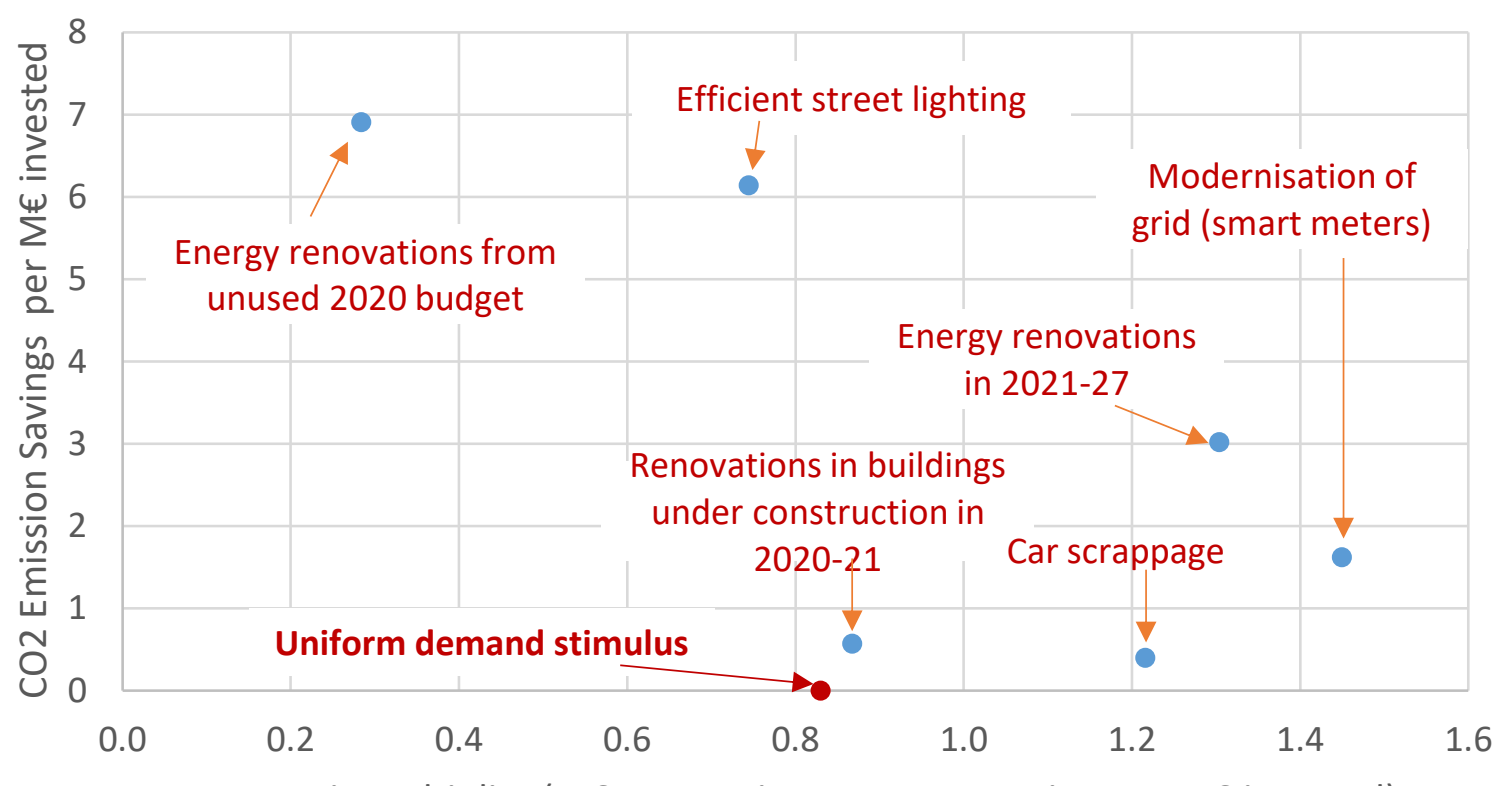

Economic Multiplier (M€ economic output generation per $\mathrm{M} €$ invested)

2

Figure 2: Relationship between short-term impact of measures on economic output and employment (a) and between short- 


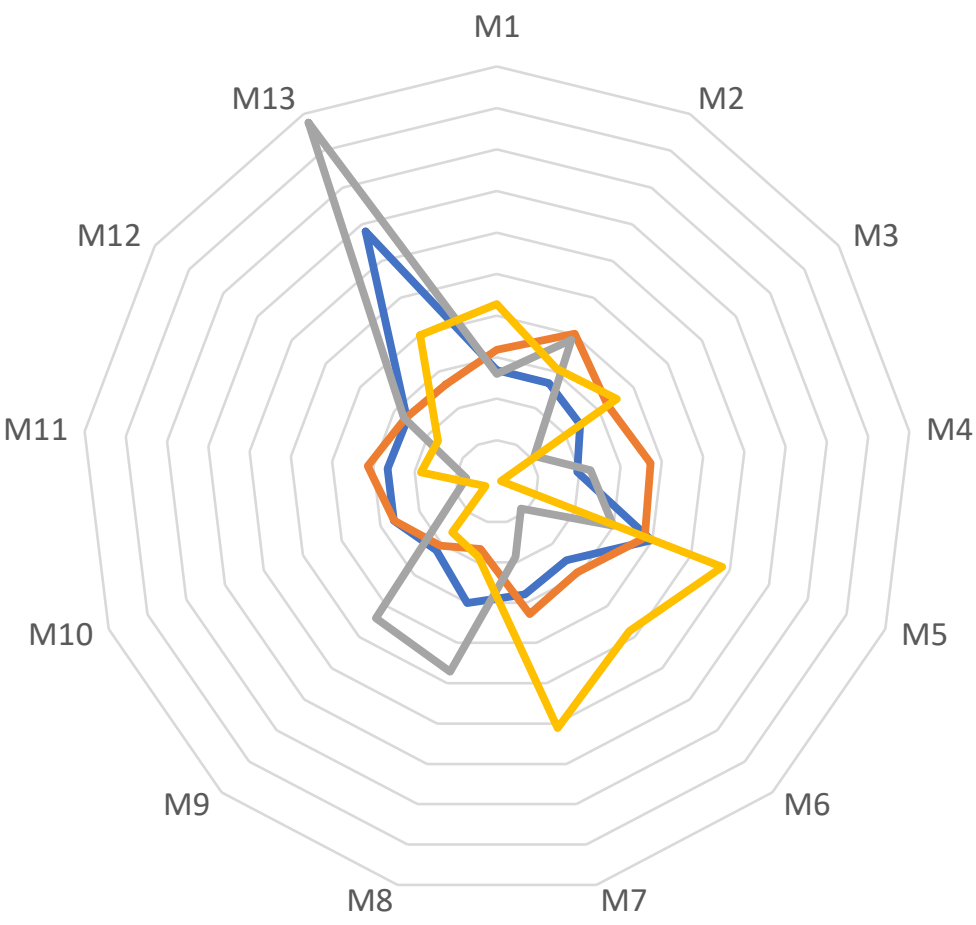

1

Short-term Environmental

Short-term Economic

Long-term Environmental

- Long-term Economic

Figure 3. Evaluation of recovery measures M1-M13 based on the average input of all stakeholders.

\begin{tabular}{|c|c|}
\hline Measure no. & Measure description \\
\hline M13 & $\begin{array}{c}\text { Fiscally neutral carbon tax reform for sectors out } \\
\text { of the EU Emissions Trading System } \\
\text { Virtual net billing for encouragement of } \\
\text { photovoltaic installations }\end{array}$ \\
\hline M5 & $\begin{array}{c}\text { New grants for energy renovations of existing } \\
\text { buildings, 2021-27 }\end{array}$ \\
\hline M2 & $\begin{array}{c}\text { Grants to enterprises with verified low-carbon } \\
\text { action plan up to 2030 }\end{array}$ \\
\hline M7 & $\begin{array}{c}\text { Immediate launch of grants for energy } \\
\text { renovations from unused budget of 2020-21 } \\
\text { Sustainable Urban Mobility Plans }\end{array}$ \\
\hline M8 & $\begin{array}{c}\text { Subsidy to loans of green businesses } \\
\text { M6 }\end{array}$ \\
\hline M9 & \begin{tabular}{c} 
Construction of tram in the capital city of Nicosia \\
\hline M12
\end{tabular} \\
\hline M3 & $\begin{array}{c}\text { Energy renovations of buildings under } \\
\text { construction within 2020 }\end{array}$ \\
\hline M4 & Installation of smart electricity meters \\
\hline M11 & Energy efficient street lighting \\
\hline M10 & Replacement of old cars with electric vehicles \\
\hline
\end{tabular}




\section{Discussion}

2 Our analysis illustrates the importance of combining simple methods with more sophisticated models

3 for an assessment of recovery measures that can provide meaningful support to policymakers.

4 Moreover, our findings clearly demonstrate trade-offs between the short term (2022), the long term

5 (2030) and the climate neutrality (2050) targets, as well as the superiority of many green measures in comparison to business-as-usual demand stimulus. Some immediate measures with attractive shortterm impact have short-lived benefits and turn out to be inferior in both economic and environmental terms by 2030 . This is in line with the finding of Barbier ${ }^{9}$ that a different policy mix is required for short-term interventions as compared to a medium to long-term strategy for a recovery leading to a green transition. Institutional or regulatory changes, such as the gradual implementation of carbon pricing or the reform of electricity rules to enable decentralised power generation, may have longterm impacts with low cost. Blunt economy-wide demand stimulus measures are not only environmentally unsustainable but also economically mediocre - they perform worse in promoting economic growth and employment than most of the green measures examined in this paper. This provides solid quantitative evidence (which can be found in very few studies in the literature) against a 'return-to-normal' stimulus. The final ranking of appropriate measures, benefiting from input by diverse societal stakeholders, contributes to the 'democratisation' of the policy formulation process ${ }^{24}$ and enables ownership of the measures by national decision makers. Linking the sustainability criteria with the UN Sustainable Development Goals facilitates the alignment of national recovery programmes with the EU and international policy agenda.

This analysis provides useful insights into the opportunities to green the post-pandemic recovery. However, it needs to be complemented by a broader look at the full package of recovery measures, including those that are not directly related to energy, climate change, and nature. For instance, public investments will be directed to health and social care infrastructures as well as information and communication technology, and green and climate considerations will need to be included in the 
1 design of these investments. Modernisation of hospitals and schools increases welfare of the

2 population and, if it includes e.g. energy efficiency renovations and proper management of hazardous

3 waste, can as well improve resilience and reduce carbon emissions.

$4 \quad$ It is always possible to do more analyses and mobilise more sophisticated models to cover more

5 dimensions of the problem and refine the policy prioritisation process. At the same time, a crisis by

6 definition is a situation where timeliness is critical, and it would not make sense to take years to

7 provide the ideal recovery package. Our two-step approach - combining modelling when tools and

8 data are available, and experts' and stakeholders' opinion to complement quantified results and

9 prioritise action - is one solution to find a compromise between timeliness and confidence, and to

10 ensure that decision makers do not have to apply blindly the result of a model. Because this approach

11 is transparent and can cope with missing data and fragmented models, it can be applied in multiple contexts for sustainable economic recovery and climate compatible growth, including where data and models are less easily available than in the European Union. 


\section{Methods}

\section{Workflow}

The lockdown measures to contain spread of the pandemic led to a serious economic downturn in Cyprus, with GDP contracting by $11.9 \%$ in the second quarter of $2020{ }^{25}$. As in most other world regions, economic stimulus packages had to be designed so as to be implemented quickly and to contribute to positive growth and employment impacts in the short term, keeping in mind long-term development and decarbonisation objectives, e.g. the EU-wide goal towards net zero greenhouse gas emissions in 2050, as foreseen in the 'European Green Deal' ${ }^{26}$, along with the legally binding obligation for ambitious emission reductions already in 2030. To address these multiple requirements, it was necessary to identify green economic recovery measures that had already been identified in the public discourse which might be promising in economic and environmental terms.

We started from existing plans announced by the Finance Minister of Cyprus in May 2020 as well as from measures included in the National Energy and Climate Plan that was submitted to the European Commission in January $2020^{27}$. Similarly, if the framework is applied in a non-EU country, the approach might begin with a breakdown of the measures included in a country's Nationally Determined Contribution (NDC) to the UN Framework Convention on Climate Change. In summary, the approach involves proposing interventions which expand measures already announced or planned by national authorities; receiving feedback from stakeholders to obtain a first reality check; assessing measures with proper criteria that account for multiple sustainability objectives in the short and long term; and prioritising measures on the basis of this assessment and considering the available budget.

Above all, it was important to ensure active participation of decision makers in the process, by using quantitative models that are open-source and available to national authorities as well as transparent workflows. This enables officers from Ministries to provide input at various stages of this work, and overall accountability of the process. In so doing we tend towards U4RIA guidelines. U4RIA is an 
1 acronym for Ubuntu, Retrievability, Reusability, Repeatability, Re-constructability, Interoperability

2 and Auditability. It aims to further good governance and sound scientific principles to energy

3 modelling for policy support ${ }^{28}$.

4 In more detail, the workflow consisted of the following stages:

1. Screening and preliminary assessment of potential green stimulus measures. In April 2020 we published a policy brief, alerting policymakers on the need to ensure that economic stimulus measures would enable the green transition ${ }^{29}$. We identified a first list of measures that could be implemented within a short period and could positively affect both employment and the environment.

2. Dissemination of the list of measures and stakeholders' feedback. The initial list of green recovery measures was circulated to Ministries of Finance, Environment, Energy and Transport, European Commission officials, NGO representatives and academics. Stakeholders focused on the need to ensure low administrative burden to allow fast implementation, and the importance of aligning the proposals with early measures announced by the national government.

3. Interaction with national business associations. In mid-May 2020, after the first wave of the pandemic had been contained and public discussions started focusing on the 'return to normality', the national Federation of Employers and Industrialists (OEB) set up a working group on the green restart of the economy, in which we participated. OEB used our proposals as a starting point and supplemented them with additional measures targeted to enterprises.

4. Enriched list of stimulus measures sent to the Finance Minister. Based on the discussions in OEB's working group, a revised list of green stimulus measures was sent to the Finance Minister of Cyprus in mid-June 2020. Three types of measures were included:

- Those which complemented general stimulus measures that had been announced by the Finance Minister some days before; 
- Measures that had already been foreseen in the National Energy and Climate Plan of Cyprus;

- New measures that could be implemented quickly, including institutional reforms that could have a long-lasting impact on the way to climate neutrality in 2050.

Thirteen interventions were identified in this way, which are listed in Table 1. More details about each measure are provided in Appendix A of the full report of the study ${ }^{30}$.

5. Preparing a list of criteria for the assessment of recovery measures. A list of sustainability criteria was created, using as a starting point a comprehensive checklist developed by the World Bank ${ }^{10}$ especially for post-COVID19 economic stimulus interventions. As some of those criteria were less relevant for the green measures considered here or would lead to the same score for all measures, these were omitted. Two more criteria were added: the technical and/or financial viability of each measure, and its anticipated social acceptance, related to its affordability. Table 2 shows the list of criteria used in this paper, linked to specific SDGs.

6. Identifying the appropriate methodology to assess impacts. For each measure it had to be determined whether the energy, climate, and employment impact could be assessed through simple calculations or with the aid of models available for Cyprus. For some measures, such as energy renovations in buildings, models are not available (there is no detailed model of the current building stock), so that the analysis had to rely on simple calculations. For other measures, such as those related to promotion of public transport or low-emission vehicles, the existing OSeMOSYS model of the Cypriot energy system can calculate short- and long-term effects on energy consumption and emissions of greenhouse gases and air pollutants. Economic impacts can sometimes be modelled through the available input-output model of the Cypriot economy, but others require a qualitative assessment based e.g. on the percentage of domestic capital and labour inputs for the considered activity. Taliotis et al. ${ }^{31}$ describe the energy and economic models in more detail. Since these models are open-source, available to national authorities, and have 
7. Assignment of scores and weights for each sustainability criterion. After the model-based energy and economic assessment of the measures was completed, qualitative assessments followed for the rest of the criteria. Stakeholder input was sought, and a specific workshop was organised with representatives of different governmental departments, the private sector, and NGOs. Each stakeholder provided a score of each recovery measure by criterion and a weight for all criteria.

8. Prioritisation of measures. Stakeholder data were processed and, along with model-based results, provided a final ranking of the proposed interventions. These were communicated to all decision makers (DMs). Governmental authorities are able to use them for prioritising measures in their recovery strategy.

\section{Simulations with energy and economic models}

Energy and environmental simulations. The assessment of the effect of green interventions on energy use and air emissions was carried out with OSeMOSYS, a long-term bottom-up energy systems model, whose objective function is the minimisation of the discounted system cost, satisfying all exogenously defined demands for energy services within a set of context-specific constraints ${ }^{12}$. Some of the input to OSeMOSYS is provided by a separate energy forecast model ${ }^{32}$, which projects final energy consumption across the economy and the related energy expenditures of households and businesses. The application of OSeMOSYS for the energy system of Cyprus is described in detail in previous studies $31,33$.

For this specific study, OSeMOSYS was used to quantify impacts related to measures 8, 9, 10 and 13: the implementation of existing Sustainable Urban Mobility Plans (SUMPs), the construction of the tram line in the capital city of Nicosia, the scrappage scheme for old cars to be replaced with battery 
electric vehicles, and the gradual implementation of a fiscally neutral carbon taxation system for sectors that do not fall within the EU Emissions Trading System (ETS). The first two of these measures are included in the country's National Energy and Climate Plan ${ }^{27}$, while the latter two interventions have already been under consideration by the government. The model output focused only on benefits related to energy savings and carbon emission reductions; improvements in air quality and congestion, which are essential benefits of sustainable mobility measures, were not considered explicitly but were included in a qualitative manner in the criterion 'other environmental impacts' of Table 2.

Implementation of SUMPs entails an effort to achieve a considerable shift away from private vehicles to sustainable modes of transport (i.e. public transport, cycling and walking). The techno-economic characteristics for each technology option in these modes is available in the existing base literature ${ }^{34}$. The development of the tram line in Nicosia, which is planned to come into operation in 2028 , is closely related to SUMPs; that project will further enable the adoption of sustainable mobility and is assumed to reduce the annual mileage of private passenger cars and motorcycles by 540 and 16 million vehiclekilometres respectively. According to the feasibility study conducted by national authorities, the tram line will have an upfront cost of approximately $€ 225$ million and annual operation and maintenance costs of $€ 12$ million ${ }^{35}$. It is estimated that it will serve up to 17.9 million passengers in year 2030 , while it will have an annual electricity demand of about 9,130 MWh.

The third measure that relates to the transport sector is the scrappage of vehicles, which have a first registration date older than fifteen years, and their replacement with battery electric vehicles. For a maximum replacement rate of 200 vehicles per year with a grant of $€ 5,000$ per vehicle, this measure will require public funds of $€ 1$ million annually. Overall, it is assumed that 400 vehicles will be replaced through this scheme. Finally, a carbon tax on fuels for sectors that do not fall within the EU ETS is assumed to be implemented gradually and reach $€ 120$ per tonne of $\mathrm{CO}_{2}$ by 2025 . This will encourage the adoption of energy efficiency measures and increasing the attractiveness of low-carbon energy 
1 technologies, such as heat pumps in the heating and cooling sector and electric vehicles in the 2 transport sector.

3 Economic modelling. Input-Output (IO) analysis is a quantitative technique for studying the 4 interdependence of production sectors in an economy over a stated time period ${ }^{36,37}$. Here we applied 5 a continuous demand-driven 10 model with disequilibrium adjustment processes to assess the 6 economy-wide effects of the selected energy-related economic recovery measures. The assumptions 7 and the application of the model for the evaluation of energy policies in Cyprus are described in detail 8 in Taliotis et al. ${ }^{31}$. Projected annual expenditures, including capital investments and operation and 9 maintenance costs, from the OSeMOSYS model are introduced to the IO model to reflect changes in the investment demand of economic sectors as a result of each one of the thirteen measures of Table 1. Expenditures are classified in seven categories: industrial equipment, power generation technologies, electricity storage technologies, gas infrastructure, public transport, private transport, and buildings (including energy efficiency measures, heat pumps, solar water heaters etc.). Projected annual energy consumption expenditure of households is introduced to the IO model to estimate the multiplier effect of changes in private consumption. Tables in Appendix B of the full report of the study ${ }^{30}$ present the distribution of annual spending associated with investments and private consumption by sector of economic activity for each recovery measure.

The initial static equilibrium conditions of the 10 model, which serve as the reference case, are based on the latest available national symmetric IO table of Cyprus for the year 2016. The national table, which includes 65 sectors of economic activity, was aggregated into 20 economic sectors, which is presented in Appendix B of the full report. The demand growth rates for the economic sectors are defined based on the GDP projections for the period up to 2030 , including the impact of COVID-19 pandemic, and were obtained from the Ministry of Finance. For 2020 we assumed a decline in the growth of the Cypriot economy (-7.4\%) across all economic sectors, and for 2021 a strong economywide recovery (+6.1\%). From 2023 onwards, growth rates return to usual levels following the official 
1 national macroeconomic outlook. Some of the recovery measures listed in Table 1 involve energy savings and hence induce a decrease in private consumption for energy, traded products, and services. We assumed that this reduction of spending, after accounting for household savings (we assumed a household saving rate of $2.4 \%$ of disposable income in Cyprus, in line with Eurostat ${ }^{38}$ ), will return to the economy and induce a rise in consumer demand for goods and services in line with the current consumption expenditure of Cypriot households ${ }^{39}$.

Finally, apart from the thirteen selected green recovery measures, we explored the macroeconomic effects of a counterfactual scenario, which would be to provide uniform economy-wide demand stimulus ('helicopter money') to Cypriot consumers. In this scenario, we aggregated the capital investments of all measures, amounting to 395 million Euros'2020 up to 2022 as shown in Table 1, and reallocated them in the economy according to the current sectoral shares of final demand.

\section{Multi-criteria assessment}

Overview of the assessment framework. Multi-criteria decision analysis (MCDA) has been developed to support DMs, especially when facing decisions involving multiple and potentially competing objectives ${ }^{24}$. In the last decades, several methods have been developed for many types of decision problems. MCDA techniques have been widely applied in a variety of fields, including energy and environment ${ }^{40-44}$. Two of the most common methods used in MCDA problems are the Analytical Hierarchy Process (AHP) method and the Preference Ranking Organisation Method for Enriching Evaluation (PROMETHEE) ${ }^{45,46}$. There are several examples of applications of AHP and PROMETHEE in the fields of energy planning, selection of energy projects, and sustainable supply chains $19,47,48$. PROMETHEE has also been used in the development and evaluation of scenarios for energy planning ${ }^{49,50}$ and for evaluating market opportunities for renewables ${ }^{51}$. 
1 AHP and PROMETHEE can be combined, as shown by several studies so far ${ }^{52-54}$. AHP can be used to

2 produce the weights of each criterion for each DM, which would be used as an input for applying

3 PROMETHEE to produce the ranking of the actions. A similar framework has been developed in Matlab ${ }^{\circledR}$ for this paper, using a PROMETHEE Group Decision Support System (GDSS) approach.

Appendix $\mathrm{C}$ of the full report ${ }^{30}$ provides technical information about the application of these methods. In summary, AHP is a pairwise comparison method which uses a ratio scale that does not require any units. DMs express their preferences for one alternative over another one, using a 1-9 scale, which is assumed to offer the appropriate flexibility. In the framework of this study the 23 criteria shown in Table 2 have been divided into two broad categories of short- and long-term impacts and further subdivided into two subcategories, namely: (i) environmental criteria, and (ii) economic/social criteria.

For the evaluation and ranking of the alternatives the PROMETHEE method has been applied. The independent experts were asked to provide a score of each alternative recovery measure (or action as it is called in PROMETHEE terminology) for each criterion in a typical 1-5 scale ranging from 'very low' to 'very high' impact. As several DMs provided input, the PROMETHEE GDSS was then implemented to combine the scores of individual DMs and produce a global evaluation that leads to the final ranking of measures.

Stakeholder Input. A variety of stakeholders were invited to act as DMs and provide input for this assessment. The group of DMs consisted of ten stakeholders: three economic planning officers from the Finance Ministry, one tax officer from the Finance Ministry, one officer from the Ministry of Energy, one officer from the Ministry of Transport, one from an energy NGO, one from an environmental NGO, and two from the national Federation of Employers representing the private sector. At the workshop, participants were informed in detail about the list of recovery measures and the evaluation criteria, and were then provided with the respective tables to fill in, applying elements of the AHP and PROMETHEE methods. The tables that each DM had to fill in are provided in Appendix 
1 D of the full report. Weighting of the different criteria according to each DM's preferences, in line with

2 the AHP method, was carried out through a piecewise comparison between each criterion. All input

3 required for the application of the AHP method was checked for consistency. In all cases, the

4 consistency ratio was calculated and was found to lie below the threshold of $10 \%$, so that the input of

5 all DMs was considered to be consistent.

6 Next, the PROMETHEE II method was applied in which each DM evaluated the performance of all

7 green interventions with a score in the scale 1-5, indicating an evaluation ranging from 'very low' to

8 'very high'. Scores for each recovery measure by criterion, in line with this method, were provided by

9 each stakeholder as shown in Appendix $\mathrm{C}$ of the full report ${ }^{30}$. It should be noted that the scores for

10 four criteria (energy savings, carbon emission savings, economic multiplier, and new jobs created)

11 have been calculated through simulations with the relevant aforementioned models, therefore stakeholders could not change these scores.

Before arriving at the final results, it was necessary to calculate the net flow from the input of each stakeholder. The final step was the application of PROMETHEE GDSS to calculate the global ranking of all measures, assuming that each one of the ten stakeholders has the same weight. Obviously, the ranking of alternatives is affected by both the weights assigned by each DM and their respective scoring by measure and criterion.

\section{References}

1. IEA. Sustainable Recovery. (2020).

2. IRENA. The Post-COVID recovery: An agenda for resilience, development and equality. (International Renewable Energy Agency, 2020). 
1 3. UN. Shared Responsibility, Global Solidarity: Responding to the Socio-economic Impacts of COVID-

2

3 19. https://www.un.org/sites/un2.un.org/files/sg_report_socioeconomic_impact_of_covid19.pdf (2020).

4. World Bank. Global Economic Prospects, June 2020. (Washington, DC: World Bank, 2020). doi:10.1596/978-1-4648-1553-9.

5. IISD et al. Track funds for energy in recovery packages. Energy Policy Tracker https://www.energypolicytracker.org/ (2020).

6. Vivid Economics. Greenness of Stimulus Index. Vivid Economics https://www.vivideconomics.com/casestudy/greenness-for-stimulus-index/ (2020).

7. EEA. The European environment: state and outlook 2020: knowledge for transition to a sustainable Europe. (Publications Office, 2019).

8. Strand, J. \& Toman, M. 'Green Stimulus,' Economic Recovery, And Long-Term Sustainable Development. (The World Bank, 2010). doi:10.1596/1813-9450-5163.

9. Barbier, E. B. Greening the Post-pandemic Recovery in the G20. Environ Resource Econ 76, 685703 (2020).

10. Hammer, S. \& Hallegatte, S. Planning for the economic recovery from COVID-19: A sustainability checklist for policymakers.

World Bank Blogs https://blogs.worldbank.org/climatechange/planning-economic-recovery-covid-19-coronavirussustainability-checklist-policymakers (2020).

11. UN. Sustainable Development Goals. United Nations Sustainable Development https://www.un.org/sustainabledevelopment/.

12. Howells, M. et al. OSeMOSYS: The Open Source Energy Modeling System: An introduction to its ethos, structure and development. Energy Policy 39, 5850-5870 (2011).

13. Popp, D., Vona, F., Marin, G. \& Chen, Z. The Employment Impact of Green Fiscal Push: Evidence from the American Recovery Act. https://www.nber.org/papers/w27321 doi:10.3386/w27321. 
1 14. Chen, Z., Marin, G., Popp, D. \& Vona, F. Green Stimulus in a Post-pandemic Recovery: the Role of Skills for a Resilient Recovery. Environ Resource Econ 76, 901-911 (2020).

15. Pollitt, H. Assessment of Green Recovery Plans after Covid-19. 37 https://www.wemeanbusinesscoalition.org/wp-content/uploads/2020/10/Green-RecoveryAssessment-v2.pdf (2020).

16. IMF. World Economic Outlook - A Long and Difficult Ascent. https://www.imf.org/en/Publications/WEO/Issues/2020/09/30/world-economic-outlookoctober-2020 (2020).

17. Vogt-Schilb, A. \& Hallegatte, S. Marginal abatement cost curves and the optimal timing of mitigation measures. Energy Policy 66, 645-653 (2014).

18. Sotiriou, C. \& Zachariadis, T. Optimal Timing of Greenhouse Gas Emissions Abatement in Europe. Energies 12, 1872 (2019).

19. Zelt, O., Krüger, C., Blohm, M., Bohm, S. \& Far, S. Long-Term Electricity Scenarios for the MENA Region: Assessing the Preferences of Local Stakeholders Using Multi-Criteria Analyses. Energies 12, 3046 (2019).

20. Elliott, R. J. R., Schumacher, I. \& Withagen, C. Suggestions for a Covid-19 Post-Pandemic Research Agenda in Environmental Economics. Environ Resource Econ 76, 1187-1213 (2020).

21. Klenert, D. et al. Making carbon pricing work for citizens. Nature Clim Change 8, 669-677 (2018).

22. Engström, G. et al. What Policies Address Both the Coronavirus Crisis and the Climate Crisis? Environ Resource Econ 76, 789-810 (2020).

23. Zachariadis, T. Proposal for a Green Tax Reform in Cyprus. Cyprus Economic Policy Review 10, 127139 (2016).

24. Jordan, A. \& Turnpenny, J. The Tools of Policy Formulation. (Edward Elgar Publishing, 2015). doi:10.4337/9781783477043. 
1 25. Cystat. GDP Growth Rate, 2nd Quarter 2020. Statistical Service of Cyprus https://www.mof.gov.cy/mof/cystat/statistics.nsf/All/8929DD38FE3C9B2DC22585210040050C? OpenDocument\&sub=1\&sel=1\&e=\&print (2020).

26. European Council. European Council conclusions, 12 December 2019. https://www.consilium.europa.eu/en/press/press-releases/2019/12/12/european-councilconclusions-12-december-2019/ (2019).

27. Republic of Cyprus. Cyprus' Integrated National Energy and Climate Plan. https://ec.europa.eu/energy/sites/ener/files/documents/cy_final_necp_main_en.pdf (2020).

28. DFID. Synthesis Report on the "Fourth Roundtable Discussion on Strategic Energy Planning". https://energyeconomicgrowth.org/sites/eeg.opml.co.uk/files/201910/Synthesis\%20Report\%20Trieste\%20Roundtable\%20June\%202019.pdf (2019).

29. Zachariadis, T. Ideas for a Green Economic Recovery of Cyprus. Economic Policy Commentary, University of Cyprus (2020).

30. Zachariadis, T. et al. "Building Back Better" in Practice: A Science-Policy Framework for a Green Economic Recovery After COVID-19. Economics Research Centre, University of Cyprus (2020).

31. Taliotis, C., Giannakis, E., Karmellos, M., Fylaktos, N. \& Zachariadis, T. Estimating the economywide impacts of energy policies in Cyprus. Energy Strategy Reviews 29, 100495 (2020).

32. Zachariadis, T. \& Taibi, E. Exploring drivers of energy demand in Cyprus - Scenarios and policy options. Energy Policy 86, 166-175 (2015).

33. Taliotis, C., Rogner, H., Ressl, S., Howells, M. \& Gardumi, F. Natural gas in Cyprus: The need for consolidated planning. Energy Policy 107, 197-209 (2017).

34. Taliotis, C. et al. The Effect of Electric Vehicle Deployment on Renewable Electricity Generation in an Isolated Grid System: The Case Study of Cyprus. Front. Energy Res. 8, (2020).

35. Ministry of Communication and Works, Public Works Department. Consultancy Services for A Feasibility Study for a Tramway System in Nicosia - Final Feasibility Study Report. (2015). 
1 36. Miller, R. E. \& Blair, P. D. Input-Output Analysis: Foundations and Extensions, Second Edition. (Cambridge University Press, 2009).

37. Giannakis, E. \& Bruggeman, A. Economic crisis and regional resilience: Evidence from Greece. Papers in Regional Science 96, 451-476 (2017).

38. Eurostat. Household saving rate. https://ec.europa.eu/eurostat/en/web/products-datasets//TEC00131 (2020).

39. Cystat. Mean annual consumption expenditure per household by main categories of goods and services, district, and urban/rural residence. Statistical Service of Cyprus https://www.mof.gov.cy/mof/cystat/statistics.nsf/All/87F363E108F0D3A8C225823400324BB8/ \$file/HBS-A-2015-EN-150218.xls?OpenElement (2020).

40. Ahmed, A., Sutrisno, S. W. \& You, S. A two-stage multi-criteria analysis method for planning renewable energy use and carbon saving. Energy 199, 117475 (2020).

41. Ali, G. et al. Urban environment dynamics and low carbon society: Multi-criteria decision analysis modeling for policy makers. Sustainable Cities and Society 51, 101763 (2019).

42. Baumann, M., Weil, M., Peters, J. F., Chibeles-Martins, N. \& Moniz, A. B. A review of multi-criteria decision making approaches for evaluating energy storage systems for grid applications. Renewable and Sustainable Energy Reviews 107, 516-534 (2019).

43. Kumar, A. et al. A review of multi criteria decision making (MCDM) towards sustainable renewable energy development. Renewable and Sustainable Energy Reviews 69, 596-609 (2017).

44. Liu, Y. \& Du, J. A multi criteria decision support framework for renewable energy storage technology selection. Journal of Cleaner Production 277, 122183 (2020).

45. Multiple Criteria Decision Analysis: State of the Art Surveys. vol. 233 (Springer New York, 2016).

46. Papathanasiou, J. \& Ploskas, N. Multiple Criteria Decision Aid: Methods, Examples and Python Implementations. vol. 136 (Springer International Publishing, 2018).

47. Abdullah, L., Chan, W. \& Afshari, A. Application of PROMETHEE method for green supplier selection: a comparative result based on preference functions. J Ind Eng Int 15, 271-285 (2019). 
48. Mastrocinque, E., Ramírez, F. J., Honrubia-Escribano, A. \& Pham, D. T. An AHP-based multi-criteria model for sustainable supply chain development in the renewable energy sector. Expert Systems with Applications 150, 113321 (2020).

49. Simoes, S. G. et al. InSmart - A methodology for combining modelling with stakeholder input towards EU cities decarbonisation. Journal of Cleaner Production 231, 428-445 (2019).

50. Witt, T., Dumeier, M. \& Geldermann, J. Combining scenario planning, energy system analysis, and multi-criteria analysis to develop and evaluate energy scenarios. Journal of Cleaner Production 242, 118414 (2020).

51. Andreopoulou, Z., Koliouska, C., Galariotis, E. \& Zopounidis, C. Renewable energy sources: Using PROMETHEE II for ranking websites to support market opportunities. Technological Forecasting and Social Change 131, 31-37 (2018).

52. Abdel-Basset, M., Gamal, A., Chakrabortty, R. K. \& Ryan, M. A new hybrid multi-criteria decisionmaking approach for location selection of sustainable offshore wind energy stations: A case study. Journal of Cleaner Production 280, 124462 (2021).

53. Neofytou, H., Nikas, A. \& Doukas, H. Sustainable energy transition readiness: A multicriteria assessment index. Renewable and Sustainable Energy Reviews 131, 109988 (2020).

54. Seddiki, M. \& Bennadji, A. Multi-criteria evaluation of renewable energy alternatives for electricity generation in a residential building. Renewable and Sustainable Energy Reviews 110, 101-117 (2019).

\section{Acknowledgements}

This study was partly funded by the Research and Innovation Foundation of Cyprus, under the Funding Scheme "RESTART 2016-2020 Programmes for Research, Technological Development and Innovation", co-funded by the European Regional Development Fund and the Republic of Cyprus, in the frame of the project "Supporting the Economic Recovery of Cyprus with a View to Energy and Climate Policy" (grant no. CONCEPT-COVID/0420/0008). Mark Howells' input was supported by the 
1 FCDO Climate Compatible Growth Program of the UK government. The authors are grateful to

2 stakeholders who participated at a workshop on 5 October 2020 and provided input for the multi3 criteria assessment. 
Figures

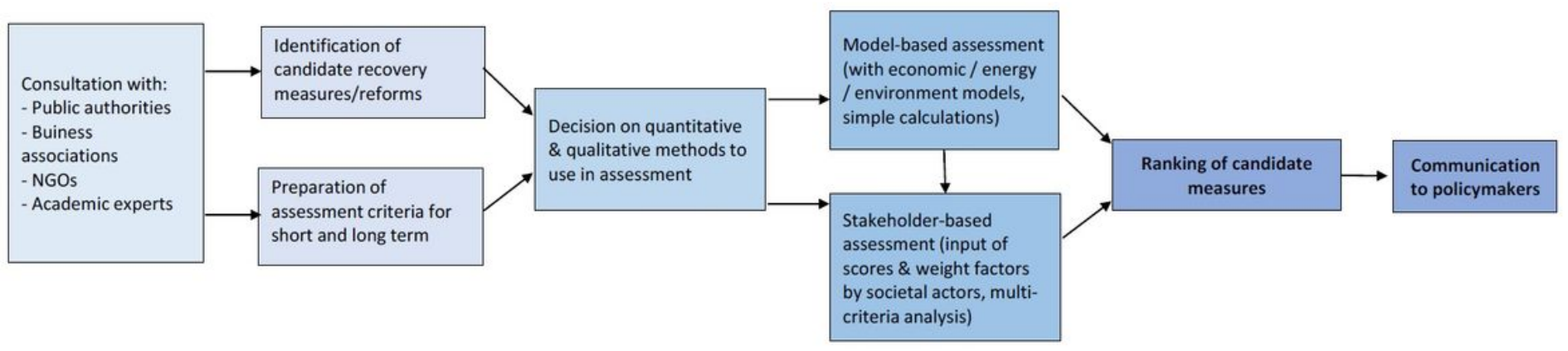

\section{Figure 1}

Approach to designing and assessing a green economic recovery strategy 
a Short-Term Economic Impact of Green Recovery Measures

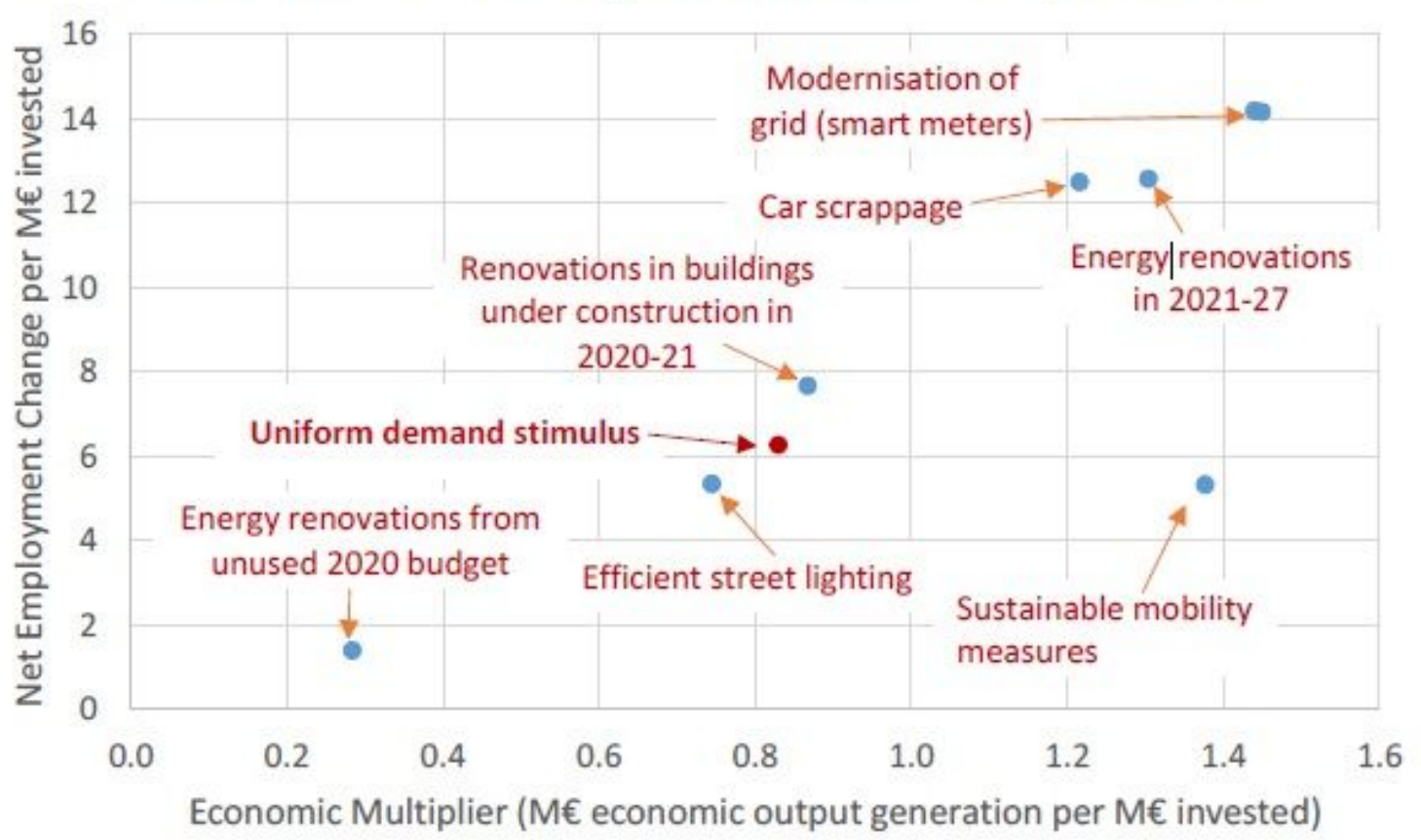

b

Short-Term Economic vs. Long-Term Environmental Impact of Green Recovery Measures

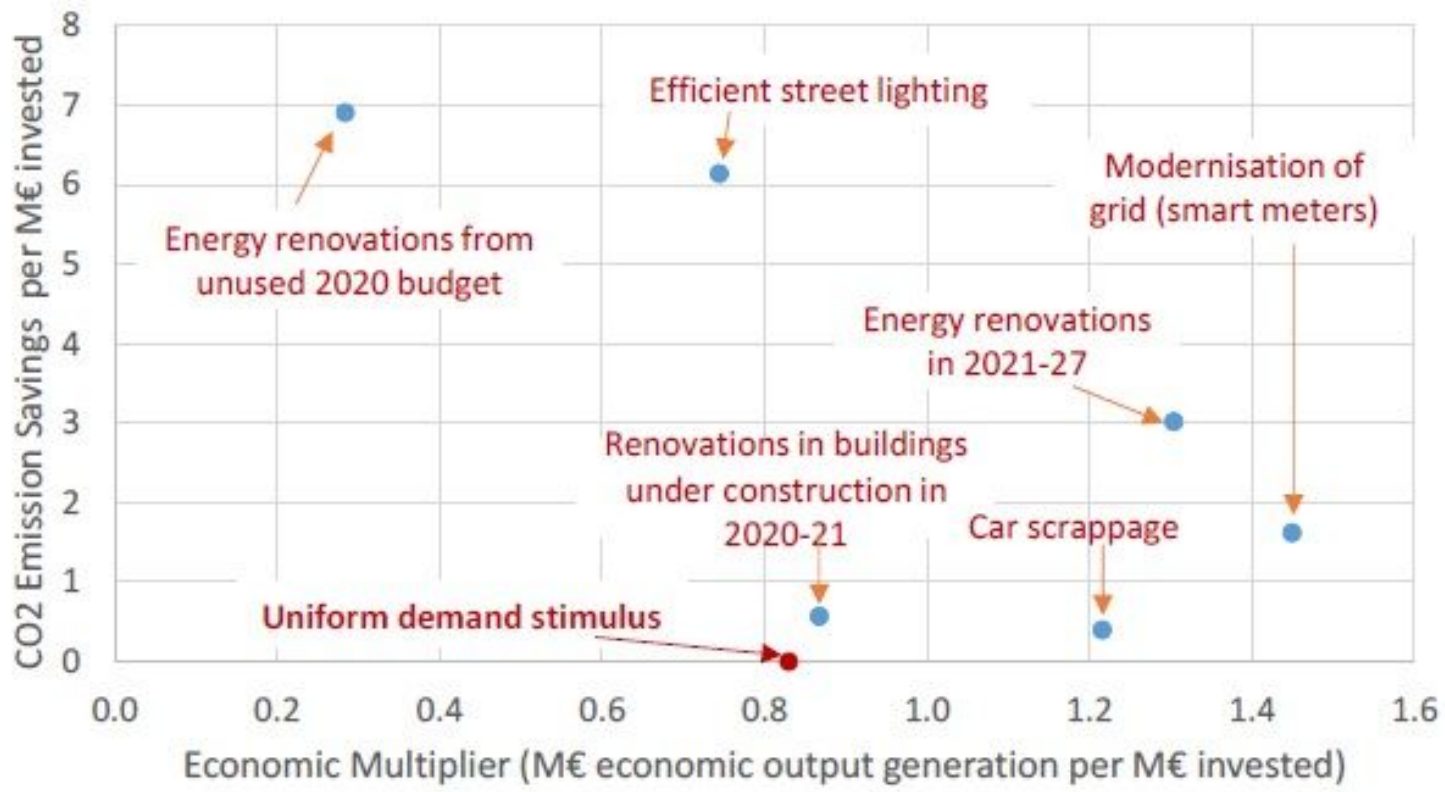

\section{Figure 2}

Relationship between short-term impact of measures on economic output and employment (a) and between short term effect on economic output vs. long-term effect on carbon emission savings (b). 


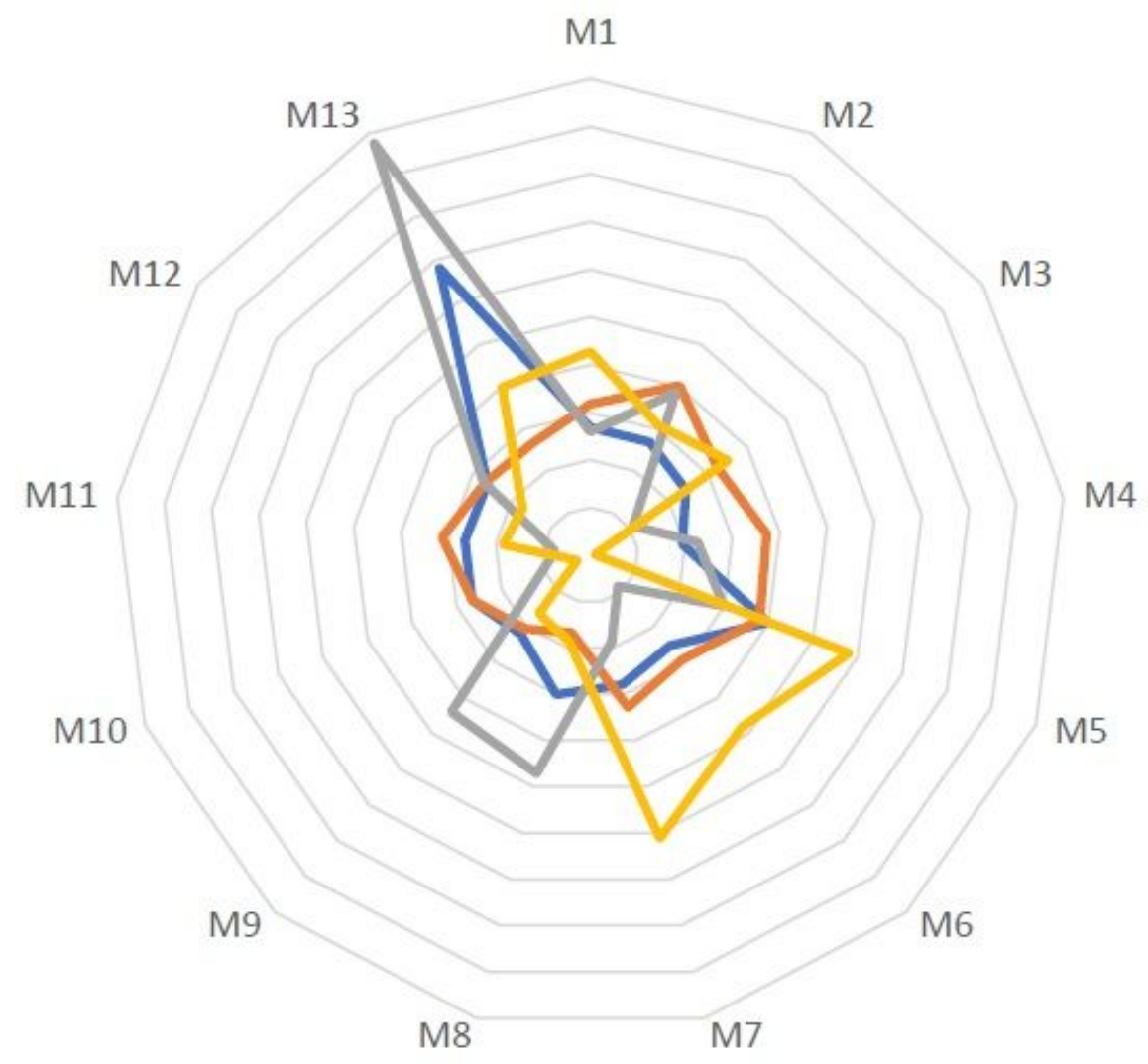

Short-term Environmental

\section{Figure 3}

Evaluation of recovery measures M1-M13 based on the average input of all stakeholders.

\section{Supplementary Files}

This is a list of supplementary files associated with this preprint. Click to download.

- DOP0520.pdf 